\title{
Examination Without Paper for Culture and Communication Course
}

\author{
Gan He \\ Institute of Foreign Languages, Wuhan Donghu University \\ Wuhan city, Hubei province, PRC. \\ E-mail: 543977811@qq.com, hegan6@hotmail.com
}

\begin{abstract}
Because of the multimodality of modern discourses, the traditional type of examination with paper for English majors is now and then being replaced by other forms of examination in teaching practice. This kind of practice is under trial because of lacking readymade model and supporting policy. A sound discussion about it would be of great help in defining the reliability and necessity of new types of examination.
\end{abstract}

Keywords-multimodality; modern discourses; multimodal resource; multimodal examination

\section{INTRODUCTION}

Holiday, a linguist's believe that there is a great variety of modes of human communication and language communication is only one of the modes. In our daily life, written language is always supported by images, graphs, tables, drawings and figures and verbal language is usually companied by rising and falling tones, different pronunciation and intonation, speed, facial expressions and body language. Modern technique equips further human communication with web, multimedia, music and visual system. Therefore, modern discourses present themselves in multimodality, which calls for a change in English lecturing pattern in China. Traditional English language education in China emphasized on the importance of conveying written language; even spoken English class was text-based. As classrooms now are usually facilitated with multimedia, more and more lecturers found themselves practicing multimodal lecturing, even new types of examination.

\section{TEXT ABUNDANT IN MULTIMODAL RESOURCES}

Take "Culture and Communication - A New Practical English Course" for example, the textbook contains eighteen units, including Associating with People, Taking Part in Social Events, Interpreting Body Language, Writing Social Letters, Using the Telephone, Going Shopping, Giving Invitation and Replies, Understanding Signs, Going to School in North America, Comprehending Common Expressions, Dining in Western Way, Staying in the Hotel, Seeking Employment, Reading Job Advertisements, Learning about Humor and Superstitious, and Making Announcements. It introduces English language and cultural background through imitation, discussion, test and questions and answers. It is rich in multimodal resources:

\section{A. Typography}

Typography is a semiotic mode. As other expressing method, its multimodality could be best found in its combination with color, structural organization, three dimensions and changing modes. The textbook is well printed with proper layout and comfortable spacing, and standard typeface etc.

\section{B. Figures, Charts, Tables and Diagrams}

Compared with typography, functions of figures, charts, tables and diagrams in teaching and learning are more obvious. Students are much easier to be attracted by them than words, so they are best used as prior knowledge before going to the text. In the textbook, the figure about tuition and education tax benefits demonstrates the net tuition and fee students paid much more clearly than hundreds of words; the diagram of hotel layout explains clearly where the Fire Exits are, and the table about idioms which divides "idiom", "meaning" and "example in three columns makes a cluster of idioms easy to remember (see Table 1).

TABLE 1 EXAMPLE OF IDIOMS WITH NAMES OF BODY PARTS

\begin{tabular}{|c|c|c|}
\hline Idiom & Meaning & Example \\
\hline Pull one's leg & $\begin{array}{c}\text { To joke about } \\
\text { something or } \\
\text { exaggerate }\end{array}$ & $\begin{array}{c}\text { "Don't pull my leg, tell me } \\
\text { the truth." }\end{array}$ \\
\hline Foot the bill & $\begin{array}{c}\text { Pay the costs or } \\
\text { expenses }\end{array}$ & $\begin{array}{c}\text { "My father is footing the bill } \\
\text { for my education." }\end{array}$ \\
\hline $\begin{array}{c}\text { Melt in one's } \\
\text { mouth }\end{array}$ & $\begin{array}{c}\text { Taste very good, } \\
\text { delicious }\end{array}$ & $\begin{array}{c}\text { "Grand mother's apple pie } \\
\text { mlts in your mouth." }\end{array}$ \\
\hline $\begin{array}{c}\text { See eye to eye } \\
\text { To agree completely }\end{array}$ & $\begin{array}{c}\text { "We get along well because } \\
\text { we usually see eye to eye." }\end{array}$ \\
\hline Out of hand & To be out of control & $\begin{array}{c}\text { "The poorly conducted meting } \\
\text { got out of hand." }\end{array}$ \\
\hline $\begin{array}{l}\text { Source: Cltures } \\
\text { P.219. }\end{array}$ & \& Communication- A & \begin{tabular}{c} 
New Practical English Course. \\
\hline
\end{tabular}
\end{tabular}

\section{Pictures}

As a proverb goes "A picture's worth a thousand words.” In our daily life, we could find books for children telling stories by pictures. The textbook under discussing is full of pictures as required by the content such as road signs (see fig.1). Pictures in discourses convey the attitude, opinion and ideology of the author. Pictures not only convey 
the information in a very condensed way, but also realize human interaction.

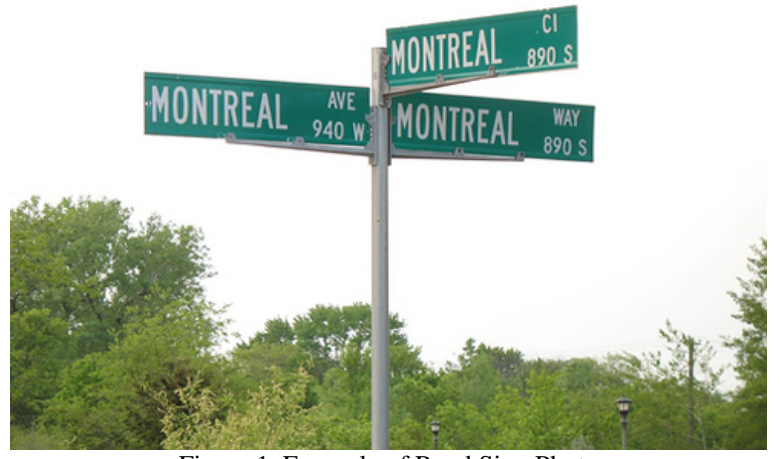

Figure 1. Example of Road Sign Photo

Source: Cltures \& Communication- A New Practical English Course. P.179

\section{Genre}

The textbook is prepared with plenty of pictures, tables, charts, diagrams, figures as well as practices and role-plays. Each unit starts with questions in both English and Chinese languages, which reduce the difficulty in understanding and stimulate students' interests. As the class went on step by step, for example, from "Face-to-Face Greeting, Role-Play, and Small Talk" etc., "New Words and Expressions" were supplemented in both languages to help students understand better. The genre of the textbook endows students to start with expectation and help them in comprehending the text through supplementary information.

\section{E. Videos}

As the arrival of information age, internet provides the richest multimodal resources for human communication, including written and verbal languages, pictures, drawings, charts, and figures, all those could be provided by books. Besides, video turns to be the most influential mode, one could listen to the music while watch the singer's performance and there are easy accesses to online movies, TV series, news, lectures, dances, sports and advertisement. One could even have a close observation of what or whom they are interested in through videos. Since most classrooms are equipped with multimedia. Internet becomes a useful teaching aid.

\section{DEVELOPING STUDENTS’ MULTILITERACIES}

\section{A. Lecture Organization}

The classes for Culture and Communication - A New Practical English Course are organized as "Quiz Show" similar to some TV shows based on the following consideration:

- The textbook contains a quite large number of language and cultural background information or facts for students to know and get acquainted with, which is actually the aim of learning the book.

- The language of the textbook is easy for students to understand. Or there isn't't much language difficulty in comprehension except a few new words that students could get familiar with by prereading before class.

- The students believe when they watch those kinds of quiz shows, they get very excited and willing to participate.

- Because of the strong will to win the quiz, students could remember facts much faster than usual.

- $\quad$ PPT and multimedia make it possible to handle.

\section{B. Students' Participation}

Students were divided into groups of three to four. Each group works as a team. Each team will organize one to two quiz shows based on the units of the textbook and take part in the quiz shows hosted by other groups. Students in each class amount from thirty five to forty students, and then about eight to ten groups would be formed in every class. Four classes of the same grade were involved. The teacher would always organize the initial one or two quiz shows to set an example for students and allow some time for students to make preparation. If it is necessary, teacher and student teams would act as organizer alternatively until the students could handle it well. The quiz shows often drew students' attention immediately. They became interested in it and trying their best to win. They got even more excited when they were told that they were going to organize quiz shows and host the quiz shows.

Not surprisingly, students organized the quiz shows successfully. Take the team which worked on body language for example, they performed the body language along with pictures in PPT. When "quiz show" began, one of the team member was chairing, while he demonstrating the definitions and making introductions, another team member was supporing him with PPT; and the third team member was performing facial expressions and different kinds of body languages, and the other one was scoring for each team on the blackboard which gave a correct answer for the facial expression or body language under question. During the quiz show, roles in the hosting team would vary because each team member would like to chair for one part of the quiz show. The rest teams competed with each other heatedly, hands rose like small woods. Sometimes it became hard for the hosting student to decide who should be given the opportunity because everyone was very speedy in putting up his or her hand. This problem was solved in the following classes innovatively by the students. They organized small and short games to decide the priority. For example, to guess the singer's name by listening to the his or her songs. Usually, students would found out the answer within seconds. This kind of small games varied from team to team, from one 
quiz show to another quiz show, always brought surprise and fun to the class.

One thing could not without mentioning was that the students downloaded quite a lot of resources from internet, including short videos such as festivals, food and parties etc.; pictures for shopping, signs and hotels etc; and they added performances for units such as Seeking Employment, Making Announcements etc. as well as various kinds of sound resources for games. The types of resources were so large in number and colorful and vivid in forms that lecturers would wonder if one lecturer could even manage them as well.

Each unit in the textbook usually took two lecturing hours, which was ninety minutes. The lecture usually went on without break simply because the quiz shows were breathtaking and the teams were so involved in and eager to win, they managed to wash hands in turns. Hearty laughs burst out now and then, some half sitting in order to get the chances for answering questions. The whole class was indulged in tense quizzes and funny games. Those language and cultural background information provided by the textbook were thus went through and even experienced.

\section{Lecturers' Roles}

- To guide and help the students, if necessary, to prepared the quiz shows. There was something worth mentioning about students organization ability. Some groups distributed their tasks equally, and in most cases, each students did almost equally well job; some group had one or two chairperson(s), the rest two or three worked as assistant(s). When asked why he or she or they did not come to chair, some of them said they had prepared the contents for quiz show, some said they prefer assisting, some just told you that he or she was too shy to chair and to be on the stage was already a challenge so he or she choose to assist. Lecturers found that some students were very good organizers who controlled the class easily; some were still hesitated whether they should try. I believe personally, in the future if those who were hesitating, had chances to chair, they would try because they observed and participated in organizing the quiz shows, the only difficulty for them was to overcome shyness which would usually solved when they getting older.

- Guiding and helping the organizers in hosting whenever necessary, such as reminding the chairperson when he or she forgot what to do next by summarizing what had been done and mentioning the next step and then leaving the floor to the hosting students; adjusting improper methods by intervening in as chairperson; as well as controlling the time for each quiz show.
- Checking the contents of the quizzes, whether they covered all required knowledge or not and if not, add supplementary questions at the end of the lectures.

- Evaluating the quality of quiz show organization by checking content coverage, time division, chance distribution, performance and game relevance etc.

\section{TEST WITH MULTIMODAL AIDS}

The examination for Culture and Communication - $a$ New Practical English Course was divided into two parts. One part was the evaluation of their organization of classroom quiz shows, the other part was the scores each team won in quiz shows. Each team finished the examination as group grades or group scores. It was a kind of new form of examination - examination without paper.

The examination took the above mentoned form in the consideration of the following reasons.

- Motivation.

Since the examination was in the form of quiz show, it would stimulate students' interest, therefore, they would like to participate in it, both as participators and organizers.

- $\quad$ Guidance.

Since students wanted to win and don't want to lose they would try their best to get familiar with the textbook through self-study and prepare their quiz shows creatively. The examination therefore guided students in learning.

- $\quad$ Definite Target

Besides, the better they did either in organizing the quiz shows or participating in the shows, the better final grades they could achieve. The target was clear and simple for each team, therefore, every team would be encouraged to reach the aim and attempted to do better than the other teams so that they would get good grades.

\section{ACKNOWLEDGMENT}

The research was financially supported by the 2012 Reseach Project of Twelth Five-Year Plan of Educational Science in Hubei Province (2012B246).

\section{REFERENCES}

[1] Holiday MAK., Language as Social Semiotic: The Social Interpretation of Language and Meaning. London, Arnold, 1978. 108126.

[2] Wang Feiping, "Developing multimodal literacies through English reading course,” in Foreign Language World, No.5, 2010 (General Serial No. 140), Shanghai Foriegn Language Education Press: 2010, pp.20-25.

[3] Luik P \& Mikk J. "What is important in lectronic text books for students of different achievement levels?” in Computrs and Education, 2008, (50): 1483-1494.

[4] Kress G, Multimodality in Cope B \& Kalantzis M (eds.). Multiliteracies: Literacy Learning and the Design of Social Futures. London: Routledge, 2000. 
[5] Kalantzis M \& Cope B, Language education and commmunication. In May S \& Hornberger N H (eds.). Encyclopedia of Language and Education ( Vol. 1), Boston: Springer Science + Business Media, LLC, 2008.

[6] Hu Zhuanglin. "Multimodalization in social semiological research" in Laguage Teaching and Research Vol. 1, 2007, pp. 1-10.
[7] New Lodon Group, “A pedagogy of multiliteracies: Designing social fitures,” in Harvard Educational Review, 1996, 6(1), pp.60-93.

[8] Ge Junli \& Luo Xiaoyan, “New conception of foreign language teaching in new media age: pedagogy of muliliteracies:, in Foreign Language World, No.5, 2010 (General SerialNo.140), Shanghai Foriegn Language Education Press: 2010, pp.13-19. 